\title{
Ethical issues in optometric practice
}

\author{
HL Sithole*
}

University of South Africa, Academic and Research Portfolio, Research Directorate, PO Box 392, UNISA, 0003 South Africa

<sithohl@unisa.ac.za>

Received 20 January 2010; revised version accepted 10 June 2010

\begin{abstract}
Ethics as a discipline is the study and analysis of values and standards related to duty, responsibility, and right and wrong behavior. The ethical obligations of optometry toward patients are similar to those of other health professionals. These obligations generally require optometrists to recognize, respect, and protect the rights of their patients. This approach encourages patients to participate actively in their care and allows them to develop a relationship with their optometrist based on trust. The ethical codes which contain guiding principles serve to help practitioners in their decisions and in practicing in accordance with a set of standards that are expected of a health care practitioner. There are four major ethical principles in health care, namely; beneficence, non-maleficence, and respect for autonomy and justice. Because these principles are easily recognized as being among the primary ethical goals of health care, using them as the basis for ethical analysis may help to explain the moral justification for certain professional actions as well as
\end{abstract}

to identify unethical behavior. However, in clinical practice, the specific demands and rationales of these broad principles may be difficult to apply. This illustrates the paradox that whilst these principles are essential tools for ethical practice, if applied too rigidly, they can be problematic. However, the goal of ethical decision making in optometry should be to identify one or more courses of action that will honor the profession's essential values while minimizing conflict with other values and professional standards. Every profession, every practice and every practitioner is governed by not only legal constraints, but also by the ethical concerns of ensuring that the patient is properly served. Considering our practices from a patient's perspective can help optometrists understand the multiple responsibilities of clinical practice. ( $S$ Afr Optom 2010 69(2) 93-99)

Key words: Ethics in optometry, principles of ethics, standards of clinical practice, health care

\section{Introduction}

Health care professionals, including optometrists, have long understood the fundamental responsibility that practitioners have toward their patients. However, it is important to introduce optometrists to ethical discourse on a variety of important topics in everyday practice and provide general guidance for optometrists faced with ethical questions in their own clinical setting. Historically, there have been ex-pec- tations placed on the behaviour of individuals within the professions that would not generally be placed on the general business person. These expectations have existed to protect patients from incompetence, uncaring or selfish exercises by professionals ${ }^{1}$. This further justifies the significance of a reflection on ethical issues that are essential complements to professionals' specialized knowledge and skills in meeting basic human needs. Ethics as a discipline is the study and 
analysis of values and standards related to duty, responsibility, and right and wrong behaviour ${ }^{2}$. Values are typically ideals that reflect the perceived worth of people, things, activities and social institutions whereas standards are typically stated expectations of performance, usually for a specific group or for a class of individuals ${ }^{2}$.

In the light of ethical rules, professionals' knowedge and skills cannot be fully understood by those whom they serve, therefore professions depend on the public's trust ${ }^{3}$. To protect the public from practitioners who would take advantage of the vulnerable, and to safeguard the trust upon which professional practice is based, professional groups and associations have historically developed formal standards of behaviour to guide the ethical conduct of their members ${ }^{4}$. In health care these standards are often written as codes of etics, which typically describe the ethical relationship that should exist between the caregiver and society, the doctor and professional colleagues and,most importantly, the doctor and patients ${ }^{4}$.

\section{Ethical principles}

The ethical obligations of optometry toward patients are similar to those of other health professionals ${ }^{4}$. These obligations generally require optometrists to recognize, respect, and protect the rights of their patients ${ }^{2}$. This approach encourages patients to participate actively in their care and allows them to develop a relationship with their optometrist based on trust $^{3}$.

While the ethical principles under which the optometric profession functions have remained relatively constant, dramatic changes in technology, the scope of optometric practice and the environment of health care delivery have created pressing new ethical questions in the clinical setting ${ }^{2}$. Ethical conflicts are evident, for example, in the use of diagnostic drugs to diagnose conditions which the optometrist is either not adequately qualified to treat or just not being allowed to treat such conditions by law. However, optometry ranks amongst the leading health care professions and various national codes of ethics for optometry exist ${ }^{5}$. These can all be traced back to one of the original sources of medical ethics in the Western world: the famous oath of Hippocrates ${ }^{5}$. The oath has been transposed through history and more recently was incorpo- rated into the Declaration of Geneva in $1984^{5}$.

The ethical codes contain guiding principles ${ }^{6}$. These serve to help practitioners in their decisions and in practicing in accordance with a set of standards that are expected of a health care practitioner ${ }^{6}$. According to Beauchamp and Childress ${ }^{7}$, there are four major ethical principles in health care, namely; beneficence, non-maleficence, respect for autonomy and justice. These principles can be described as follows:

i) Beneficence is striving to do good and to do the best for every patient. This recognizes that a practitioner has a duty of care to every patient and that paramount is the objective to do good so that every patient leaves the practice in a better state than when they entered, or at the very least, not in a worse condition.

ii) Non-maleficence, directly traceable to the Hippocratic Oath, is about the avoidance of harm. This requires balancing risks and benefits of treatment and making decisions that will optimize the benefits and minimize the risks of harm.

iii) Respect for autonomy requires a practitioner to respect the choices and decisions that a patient makes about his or her health. This involves keeping the patients informed of their condition, treatment choices and options so that decisions made are based on pertinent facts.

iv) Justice entails being fair to all patients in a way that transgresses legal justice. It includes deciding how much time is spent on a patient, how many and what types of resources are devoted to treatment of the patient and how this compares to the time and resources distributed to other patients.

In addition to beneficence, non-maleficence, respect for autonomy and justice, the principles of confidentiality, protection of the vulnerable and collegiality have been included to form the ethical principles that should guide optometric practice ${ }^{5}$. Confidentiality means non-disclosure of the patient details and health records in order to respect the privacy and preserve the dignity of each patient. Like non-maleficience, it can be traced directly to the Hippocratic Oath which states that whatever I see or hear, professionally or privately, which ought not to be divulged, I will keep secret and tell no one ${ }^{8}$.

Protecting the vulnerable involves standing up for the rights of those who may be unable to speak or act for themselves ${ }^{6}$. Although all patients are to some 
extent vulnerable as they come for help to the practitioner, some are more vulnerable than others. These include children, the frail elderly and patients who are unable to make decisions for themselves ${ }^{5}$. Whilst some of these patients may not be considered autonomous by law (such as children) and others may be mentally unable to exercise autonomy, their dignity must at all times be respected and the duty of care the practitioner owes them may require a degree of protection that extends beyond the usual duty of care ${ }^{5}$.

Collegiality calls for support of colleagues and fellow practitioners and professionals ${ }^{5}$. This is the only ethical principle that does not apply to patients but to the way practitioners treat one another. Collegiality means mutual respect and understanding for fellow optometrists, for other professionals and for their respective roles in the health care team.

Challenges in the application of ethical principles

Because these principles are easily recognized as being among the primary ethical goals of health care, using them as the basis for ethical analysis may help to explain the moral justification for certain professional actions as well as to identify unethical behavior ${ }^{5}$. However, in clinical practice, the specific demands and rationales of these broad principles may be difficult to apply5. This illustrates the paradox that whilst these principles are essential tools for ethical practice, if applied too rigidly, they can be problematic. Just like in a case of beneficence, it is easy to state that a practitioner should at all times do the best for every patient but it is also not simple to define how good is good enough. The difficulty with this principle is that it is limitless and every practitioner needs to decide how far he wants to take this principle.

Nonmalificence may not be limitless but it may be limiting 6 . No practitioner will ever set out to harm a patient, yet certain practice methods such as contact tonometry or the prescription of contact lenses may incur a risk of harm or unwanted side effects. To apply non-maleficence rigidly would require a practitioner to abandon all practice methods with the potential to harm, no matter how minimal the harm or how small the risk ${ }^{6}$. This would limit the practitioner to such an extent that some aspects of optometric practice may not be feasible.

Respecting the autonomy of a patient who refuses to wear a prescription without which he is below the legal standard for driving can pose difficulties ${ }^{5}$. The optometrist cannot always respect the choice of such patients since such behavior is unreasonable and potentially dangerous 5 .

Justice means being fair to all patients but that involves the complexity of deciding the basis of this fairness and how time and resources should be distributed $^{5}$. It would be easiest to say that all patients should be given half an hour of an optometrist's time but this may prove to be too inflexible. Some patients may need less time and some considerably more. Similarly, it may sound just to declare that the same treatment should be given with the same condition. How is this to be reconciled in a case of a ninety year old lady with cataract that leave her with unaided visual acuity of $6 / 18$ and the forty year old long distance driver with the same type of cataract and same visual acuity? Should both necessarily be referred for cataract surgery?

Confidentiality may be compromised when a patient discloses to a practitioner something that may have serious ramifications for the patient and potentially for others ${ }^{8}$. It can be very difficult for an optometrist to decide whether or not to keep confidential the details of a patient who admits to having HIV but asks the optometrist to keep this secret from his wife.

Protecting the vulnerable may require deciding how far this protection can extend. Should the parent of a child patient who appears with multiple bruising be reported even though the matter may have little to do with eye care? Reporting such a matter to social services may result in innocent parents having to defend themselves against charges of child abuse. Not reporting may leave a vulnerable child open to further risk of harm.

Collegiality is easy to practice with those who have similar interest and outlooks. It can be more difficult when working with a fellow optometrist who has different perspectives, opinions, attitudes and behavior ${ }^{8}$. If the colleague is practicing ethically, personal differences should be put aside. Collegiality also has no place for prejudice or professional jealousy ${ }^{8}$. If a colleague is behaving in a manner that may be inappropriate for a professional, collegiality cannot be used as an excuse to protect what is wrong. Help should be offered but in some cases a colleague may need to be reported.

Whenever the optometrist faces a situation in which the best ethical course of action is unclear, such 
as when actions motivated by one ethical principle or standard conflict directly with other ethical principles or standards, it can be useful to analyze the situation in a structured way before acting 5 . The goal of ethical decision making in optometry should be to identify one or more courses of action that will honor the profession's essential values while minimizing conflict with other values and professional standards ${ }^{6}$. Considering the relevant ethical issues formally may clarify the hierarchy of professional values related to the problem and may identify a wider range of acceptable options than first seemed available?

\section{Standards of conduct}

\section{Basic responsibilities of an optometrist}

According to the American Optometric Association $^{10}$, the basic responsibilities of an optometrist are divided into two, namely; the welfare of humanity and continuing competence. The welfare to humanity involves the understanding that a health profession has as its prime objective the service it can render to humanity; monetary considerations should be a subordinate factor ${ }^{10}$. It also means that in choosing the profession of optometry an individual assumes an obligation for personal conduct in accordance with professional ideals ${ }^{11}$. Continuing competence means that an optometrist should strive to keep current with modern developments in the profession to enhance both knowledge and proficiency by the adoption of modern methods and scientific concepts of proven worth, and to contribute personally to the general knowledge and advancement of the profession ${ }^{10}$. All these should be done with that freedom of action and thought that provides first for the welfare of the public ${ }^{2}$.

\section{Relationship with the patient}

In relationship with the patient, it is important that an optometrist should provide to the patient sufficient information in order to obtain an informed consent from the patient ${ }^{12}$. Informed consent serves the vital purpose of strengthening patients' participation in and control over their health care ${ }^{13}$. The spectrum of informed consent ranges from implied consent to a routine examination, in which the patient's presenting for an appointment implies the patient's willingness to be examined, to simple consent to a low-risk procedure after the patient receives basic information about the intervention, to written informed consent following the disclosure of comprehensive information and the formal signing of consent document prior to the procedure $^{13}$. The ethical principle behind informed consent is respect for autonomy.

It is also important that a request for optometric care in an emergency receives immediate response ${ }^{2}$. Once having taken an emergency case, an optometrist shall neither abandon nor neglect the patient. Such actions will strengthen the relationship between the optometrist and the patient ${ }^{2}$.

\section{Relationship with other optometrists and profession- als}

Intraprofessional and interprofessional referral and consultations are encouraged when the best interest of the patient indicates additional opinion ${ }^{14}$. Protocolonthe relationshipand responsibilities between the referring and attending optometrist or any other professional that customarily is followed by health professions shall prevail.

Every optometrist has a duty to provide the best possible care to any patient ${ }^{14}$. Many times all necessary care can be rendered in the office, but the optometrist has a responsibility to recognize that some patients may need to be seen by others outside of the practice $^{14}$. For example, when the optometrist is in doubt about the patient's diagnosis, the patient would likely benefit from a referral for a second opinion. The optometrist in such circumstances has a responsibility to suggest that a second opinion would be desirable and to recommend a qualified colleague to provide it. If the patient accepts the recommendation, the original optometrist must provide complete and useful clinical information to the colleague, who should render the requested opinion promptly, in writing, and in the language that does not ridicule the original optometrist's need for a second opinion ${ }^{15}$.

Although the patient's wishes must ultimately govern such a decision, both the original optometrist and the consultant should inform the patient from the outset that they are working together for the patient's interest, and that the consultant is not intended as a replacement ${ }^{15}$. The referring optometrist should make clear, and the consultant should clearly understand, that the patient is intended to return, and that the original optometrist remains responsible for the patient's comprehensive eye and vision care ${ }^{15}$. 
On a lighter but important note, professional responsibility also demands that the optometrist actively participate in public health activities with other health professionals to the end that every step be taken to safe guard the health and welfare of the public ${ }^{2}$. Also, any optometrist holding an official position in any optometric organization shall avoid any semblance of using this position for self aggrandizement ${ }^{15}$.

\section{Continuity of care}

The need for continuity of care is another issue in which the optometrist's duty to patients may require sharing responsibility for patients with others, and which likely requires having a formal plan in place 5 . An optometrist who thinks that his or her responsibility to patients ends at $5 \mathrm{pm}$ is mistaken, both ethically and legally ${ }^{2}$. Ensuring continuity of care clearly means that there must be some system in place for after-hours coverage for emergencies ${ }^{16}$. A system that allows a patient to contact a qualified practitioner after hours in an emergency meets the ethical test for availability; a voice on an answering machine stating that the office will be open again in the morning does not $^{16}$.

When a practice has more than one optometrist, it is likely that more than one will see the same patients over time ${ }^{16}$. After as little as one visit patients often recognize one optometrist as their eye doctor, and may expect to be treated by someone familiar at all future visits ${ }^{16}$. It is obviously not always possible for all patients to be seen by one optometrist in all their visits. However, when a patient is to be seen by an unfamiliar optometrist, it is important for the staff member who schedules the appointment to tell the patient which optometrist will provide the examination or treatment ${ }^{16}$. It may also be necessary to assure the patient that such cross coverage is a normal activity of the practice ${ }^{1}$. The optometrist who treats a colleague's patient may similarly need to reassure the patient that his or her original optometrist will still be in charge of the case ${ }^{16}$.

Providing continuity of care through crosscoverage within a practice raises two important ethical issues: fairness in dealing with colleagues, and providing the best care to patients ${ }^{16}$. In most situations, the primary means of communicating about patients' treatment by different caregivers is through the patient record. If more than one optometrist will be like- ly to see the same patient, it is essential for everyone to ensure that their records are complete and legible so that colleagues can readily establish an unfamiliar patient's diagnostic and treatment history ${ }^{2}$. The use of jargon, abbreviations, and personal shorthand should be avoided in patient records, as they may be misinterpreted and put the patient at risk of harm ${ }^{2}$. Even in a single practitioner office this should always be the standard for record keeping, for no one can predict when illness or an accident might necessitate bringing another optometrist into the practice temporarily ${ }^{2}$.

\section{Certificates and reports}

Optometrists are frequently required to issue statutory and private certificates which have little to do with improving health or relieving suffering, but certify entitlement to resources or justify absence from work. Statutory certificates may include driver's license certificates whereas private certificates may include sickness certificates ${ }^{17}$.

The writing of a certificate involves a different relationship. The optometrist is acting on behalf of the party requesting the certificate, not the patient, who becomes the object of transaction; the person on whom the optometrist is asked to give a professional judgment rather than a participant in a two sided relationship ${ }^{17}$. It is important to realize that sometimes the interest of the patient and of the third party may be similar. For example, it is not desirable that someone with low vision should hold a heavy goods vehicle license; this is true both for society and for that person -although a driver about to lose his or her job may not see it that way. Also, patients may request a sickness certificate to support a cause they wish to pursue ${ }^{17}$. Although the optometrist may be acting for the body that will receive the certificate, the optometrist could be seen as providing a service to the patient in the same way as when writing a prescription or a referral letter.

Even in this apparently more straightforward model, conflict may arise between benefiting the patient and the general responsibility to be truthful. Matters of medical judgment are seldom a clear cut; it is rarely a choice between supporting the patient and telling a lie. Rather it is a question of how the truth can be molded into the shape which best fits the patient's interests; a matter of fine ethical judgment ${ }^{17}$. Also, the Hippocratic oath ${ }^{8}$ requires health professionals to re- 
main honest and truthful at all times. This suggests that optometrists should always seek to provide truthful reports regardless of whether such reports favor the patient or not.

\section{Duration for the retention of medical records}

Medical records serve many functions but their primary purpose is to support patient care $^{18}$. A medical record may be defined as any relevant record made by a health care practitioner at the time of or subsequent to a consultation and/or examination or the application of health management ${ }^{19}$. It contains information about the health of an identifiable individual recorded by a health care professional, either personally or at his or her direction ${ }^{20}$. According to the Health Professions Council of South Africa ${ }^{21}$, medical records should be kept for a period not less than six years from the date they became dormant. This is applicable to all patients who are 21 years old and above. In a case of patients who are minors (under 18 years), medical records should be kept until the minor's 21st birthday. This is because legally mi-nors have up to three years after they reach the age of 18 years to bring a claim ${ }^{21}$. For mentally incompetent patients, their medical records should be kept for the duration of their lifetime. It is important to note that in terms of the Occupational Health and Safety Act ${ }^{22}$, health records must be kept for a period of twenty years after treatment. This calls for a good record keeping methods and standards by all health professionals. Furthermore, medical records should be kept in a non-erasable ink and erasure fluid should not be used ${ }^{21}$.

\section{Responsibilities to the public}

Vision screening programmes may also be an important tool for community eye health education ${ }^{23}$. This may be coupled with eye health promotion initiatives by the optometrists ${ }^{23}$. However, the practice of conducting community based screening as a form of outreach has critics. Not only may screening be mistaken for a comprehensive eye and vision examination, optometrists who conduct screenings may be accused of offering free screenings solely to identify individuals whose followup diagnosis and treatment will generate income. Such criticism may be valid if the optometrist is not willing to accept all patients who warrant further diagnostic testing, irrespective of the suspected condition or the patient's ability to pay for care ${ }^{23}$.

In some instances, optometrists who conductcommunityscreeningsmay provide a list of several eye care practitioners to everyone screened, enabling patients to make their own choices about where to get follow-up care ${ }^{2}$. Providing such a list may also be important when screening is conducted by lay people, and avoids the appearance that the screeners are working to generate patients for one particular optometrist ${ }^{23}$. Unfortunately, in smaller communities where there are few eye care practitioners available, it may be difficult to avoid this impression unless the optometrist is known to engage in other community services $^{23}$.

\section{Respect for statutory regulations}

The structural nature of the optometric profession requires that some optometrists act both as professional health care providers and as entrepreneurial business persons ${ }^{24}$. According to Balliet ${ }^{25}$, there are people who can deprofessionalize optometry by creating conditions which can infringe upon professional decision making and replace it with marketplace decisions based upon cost effectiveness and products. It is therefore important that an optometrist should honor the applicable provisions of laws regulating the profession as stipulated in the Health Professions Council of South Africa's guidelines for good practices $^{21}$. It is important to realize that these guidelines are not rigidly applied as they also show some level of flexibility. For example, one guideline stipulates that a practitioner shall be allowed to advertise his or her services or permit, sanction or acquiesce to such advertisement on provision that the advertisement is not unprofessional, untruthful, deceptive or misleading ${ }^{21}$. Although there is some flexibility, an optometrist should honour the applicable provisions of laws regulating the advertising of ophthalmic materials and the disseminating of information regarding professional services especially while doing community services $^{23}$. Also, it is important to note that an optometrist is not allowed to canvass or tout or even allow canvassing or touting to be done for patients on his or her name ${ }^{21}$. These regulations only seek to control and maintain professionalism upon those who wish to be judged as professionals ${ }^{25}$. Professionals are obviously not expected to defraud medical aid schemes and even over-charge patients for services. It is therefore the 
optometrist's responsibility to endeavor to maintain healthy legal and ethical practices at all times.

\section{Conclusion}

Every profession, every practice and every practitioner is governed by not only legal constraints, but also by the ethical concerns of ensuring that the patient is properly served. Considering our practices from a patient's perspective can help an optometrist understand the multiple responsibilities of clinical practice. The golden rule for treating others as we would wish to be treated should be kept in mind constantly and will help us render the kind of care we would wish to receive in a colleague's office. This places on each optometrist, the responsibility of developing personal ethical standards and the expectation of possessing the requisite self-discipline to practice in accordance with these standards.

\section{References}

1. Bailey RN. Professional behavior and the optometric profession. J Am Optom Assoc 199768 693-698.

2. Bailey RN, Heitman E. Ethics in clinical optometry: an optometrist's guide to clinical ethics. American Optometric Association, 2000.

3. Beauchamp TL, Childress JF. Principles of biomedical ethics, 4th ed. New York: Oxford Univer-sity Press, 1994.

4. Heitman E. Ethical decision making in clinical practice: an optometrist's guide to clinical ethics. American Optometric Association, 2000.

5. Pierscionek BK. Law and ethics for the eye care professional. Butterworth-Heinemann Elsevier, Edinburg, 2008.

6. Pierscionek BK. Ethics in optometric practice - the obligations that define a profession. J Am Optom Assoc 20081 5-7.

7. Beauchamp TL, Childress JF. Principles of biomedical ethics, 5th ed. New York: Oxford University Press, 2001.

8. Hippocrates. The oath. In: Chadwick J, Mann WN. Hippocratic writings. London: Penguin books, 1978.

9. Zaner RM. Ethics and the clinical encounter. Englewood Cliffs, NJ: Prentice Hall, 1988 266-282.

10. American Optometric Association. Code of ethics. St. Louis, MO: AOA, 1944.

11. American Diabetes Association. Standards of medical care for patients with diabetes mellitus. Diabetic Care 199619 8-15.

12. Bailey RN. The doctor-patient relationship: communication, informed consent and optometric patient. J Am Optom Assoc 199465 418-422.
13. Abplanalp P. Informed consent as an ethical issue in modern optometry. J Am Optom Assoc 199465 347-354.

14. Rumpakis JM. Promoting teamwork. Optom Manag 1998 33 58-60.

15. Bridwell J, Usdan M, Farkas P. Interpersonal relations. In: Classé JG et al eds, Business aspects of optometry. Boston, MA: Butterworth-Heinemann, 1997 187-196.

16. American Optometric Association. Resolu-tion 1886, adopted 1991, modified 1995. AOA House of delegate's resolution and substantive motions. Judicial council. St. Louis, MO: AOA, 1999.

17. Toon PD. Ethical aspects of medical certification by general practitioners. Brit J Gen Prac 199242 486-488.

18. Mann R, Williams J. Standards in medical record keeping. Clin Med 20033 329-332.

19. de Klerk A. The right of patients to have access to their medical records: the position in South African law. Med Law 199312 77-83.

20. Making and keeping medical records. MPS casebook 13 (international), July 2000 6-8.

21. Health Professions Council of South Africa. Guidelines for good practice in the health care professions. Booklet 14, 2008.

22. South African Department of Labor. Occupational Health and Safety Act No 85, 1993.

23. Fukai M, Matsumoto D, Neumaier R. Screening principles, public health and community optometry, 2nd ed. New York: Butterworth 1990 85-96.

24. Pullman D. Role conflict and conflict of interest: a professional practice dilemma. J Am Optom Assoc 199667 98108.

25. Balliet P. Professionals and ethical practice in optometry. $J$ Am Optom Assoc 198758 128-130. 